\title{
Incidence of Vitamin D Insufficiency in Coastal South-Eastern US Patient Population With Cardiovascular Disease
}

\author{
Sherrie Khadanga ${ }^{\mathrm{a}, \mathrm{c}}$, Clara V. Massey ${ }^{\mathrm{b}}$
}

\begin{abstract}
Background: Vitamin D insufficiency is increasingly gaining prominence as an associated cardiovascular disease (CVD) risk factor, often thought to be an issue in colder climates and higher altitudes. The intent of this study was to ascertain vitamin D levels in the southern Alabama gulf-coast region that has a high number of sunny days along with an annual average elevated UV ray index.

Methods: An observational retrospective study of 204 patients with established CVD treated at the University of South Alabama's Heart Center from January 2007 through January 2013 was undertaken. One-way ANOVA analyses were performed to determine any significant difference in the mean 25-hydroxyvitamin D (25(OH)D) serum based on gender and also based on race/ethnicity. Further, odds ratio (OR) was computed to ascertain if there was a relationship between vitamin D insufficiency and elevated body mass index (BMI).
\end{abstract}

Results: Out of 204 patients, $53.4 \%(n=109)$ were found to have vitamin D insufficiency $(25(\mathrm{OH}) \mathrm{D}=20.1 \mathrm{ng} / \mathrm{mL})$, while $46.6 \%(\mathrm{n}$ $=95)$ were within the normal range $(25(\mathrm{OH}) \mathrm{D}=37.8 \mathrm{ng} / \mathrm{mL})$. The mean $25(\mathrm{OH}) \mathrm{D}$ of the entire group was 28.3 , indicating a general trend of vitamin D insufficiency for patients treated at the cardiology clinics.

Conclusion: This study established the prevalence of vitamin D insufficiency in the hot and high UV ray index climate of the coastal south-eastern United States. Also, it revealed the relationship of increased BMI with low 25(OH)D serum level. More extensive studies should be conducted in similar climates to further assess vitamin $\mathrm{D}$ insufficiency.

\footnotetext{
Manuscript accepted for publication August 26, 2014

${ }^{\mathrm{a}}$ Department of Medicine, University of Vermont, 111 Colchester Avenue, Fletcher 311, Burlington, VT, USA

${ }^{\mathrm{b}}$ Division of Cardiology, University of South Alabama, Mobile, AL, USA

${ }^{\mathrm{c}}$ Corresponding Author: Sherrie Khadanga, Department of Medicine, University of Vermont, 111 Colchester Avenue, Fletcher 311, Burlington, VT 05401, USA. Email: sherrie.khadanga@vtmednet.org

doi: http://dx.doi.org/10.14740/jocmr1953w
}

Keywords: Vitamin D insufficiency; Serum 25-hydroxyvitamin D; Cardiovascular disease; Body mass index

\section{Introduction}

Cardiovascular disease (CVD) risk factors are multifaceted. Factors like hypertension (HTN), chronic kidney disease, hyperlipidemia (total cholesterol, LDL, HDL, and triglycerides), diabetes mellitus (DM), peripheral artery disease (PAD), C-reactive protein, obesity, smoking, and sedentary lifestyle have been of primary focus of medical treatment in clinical settings. The issue of vitamin D deficiency is gaining importance for cardiovascular risk assessment. The medical community is gradually acknowledging the association of low levels of vitamin D with an increased risk of cardiovascular events and introducing vitamin $\mathrm{D}$ supplementation in clinical settings [1-4]. However, there seems to be a general assumption that vitamin D deficiency occurs mostly in colder climates and in higher altitudes [5].

Numerous studies pertaining to vitamin $D$ have been undertaken both in the form of original research and review research. Vitamin D studies have been undertaken in the field of rheumatology [6-8], nephrology [9-11], orthopedics [1214], and endocrinology [15-17] among others. While there are studies addressing vitamin D deficiency in cardiology [18-22], relatively few of them have been undertaken in a cardiovascular setting within a university medical center specifically addressing costal populations in a hot, sunny, and high UV index environment.

The intent of this study is to ascertain vitamin D levels among cardiac patients in the southern Alabama gulf-coast region (latitude N 30.69/longitude W 88.05) [23]. This region has 218 sunny days considered to be relatively high [24] along with an annual average elevated UV ray index between 7 and 8 [25]. Additionally, a "beach culture" prevails where outdoor activities, however minimal, are a part of routine life that provides sun exposure, whether planned or not. It is postulated that any findings of this study would be of significance not only to the immediate geographical proximity, but also to other areas with similar sun exposure 


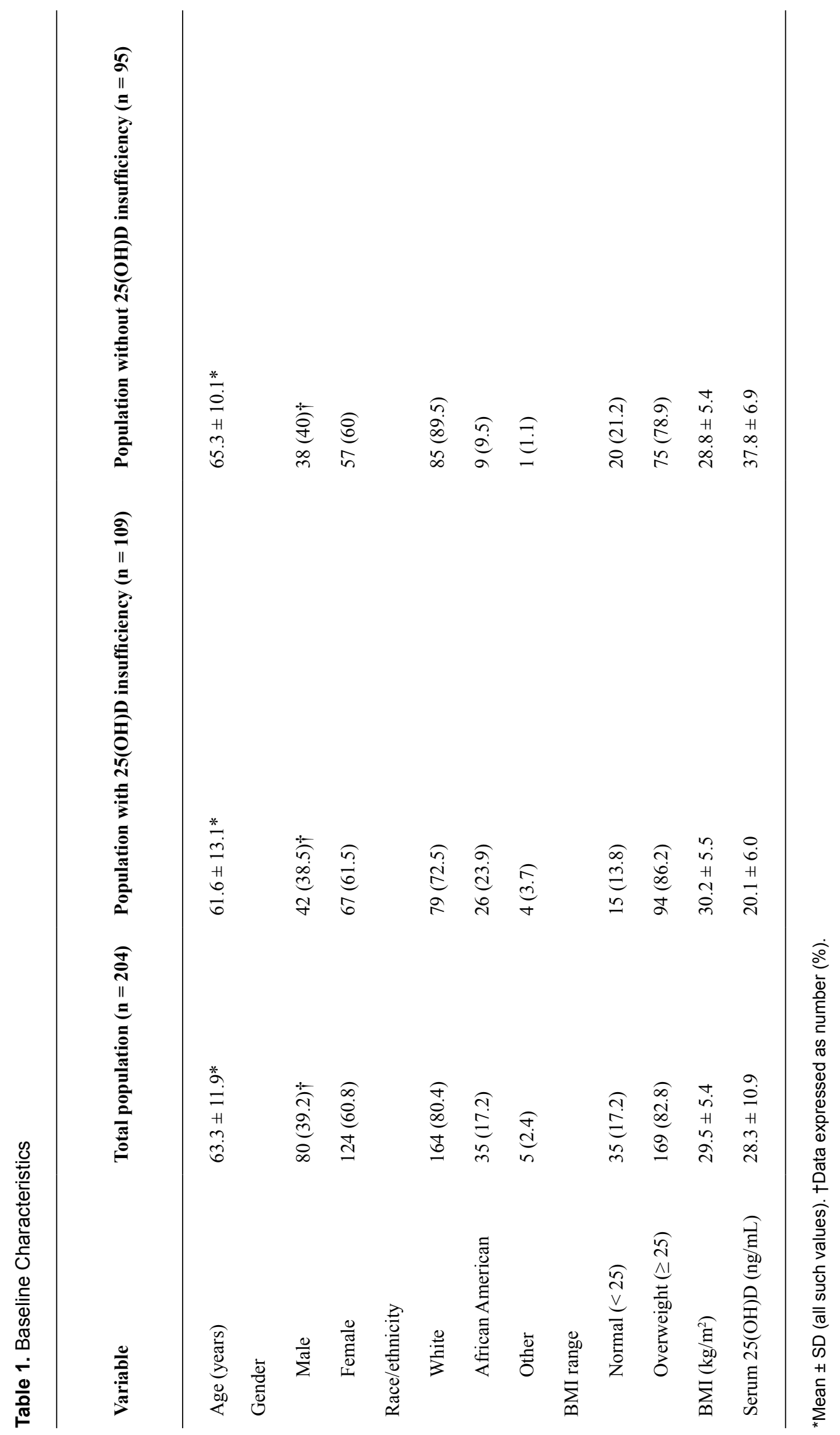


and topography.

\section{Materials and Methods}

An observational retrospective study of patients with established CVD $(\mathrm{n}=204)$ was undertaken. The study was approved by the University of South Alabama's Institutional Review Board (IRB). The patients were treated at the University of South Alabama College of Medicine (USACOM) Heart Center from January 2007 through January 2013.

The plasma metabolite of vitamin D, 25-hydroxyvitamin $\mathrm{D}(25(\mathrm{OH}) \mathrm{D})$ has been thought by researchers to be a useful risk marker in studying vitamin D deficiency [26, 27]. The determination of vitamin $\mathrm{D}$ insufficiency for the purpose of this study has been designated as a value of $25(\mathrm{OH}) \mathrm{D}$ being $<30 \mathrm{ng} / \mathrm{mL}$.

A patient chart review and pursuant data collection was done to obtain the following data points: gender, race, age, body mass index (BMI), and vitamin D serum level. BMI was calculated as weight $(\mathrm{kg})$ divided by height $\left(\mathrm{m}^{2}\right)$. BMI range was divided into two categories based on the common definitions of "normal" $(<25)$ and "overweight" $(\geq 25)$. It needs to be noted that patients with vitamin D supplementation were excluded from the study; only those without any vitamin D supplementation were considered. Being actively treated in a cardiology clinic, most patients were on statins, anti-hypertension medications, and DM therapies. Since the distinct goal of this study was to determine the incidence of vitamin D insufficiency, other observation points (lipid profile, HTN data, and A1c) were excluded.

Statistical analyses were undertaken using SYSTAT 12.0 (Systat Software Inc., San Jose, CA, USA). Descriptive statistical analysis was conducted to present the baseline characteristics (age, gender, race/ethnicity, BMI, BMI range, and serum $25(\mathrm{OH}) \mathrm{D} \mathrm{ng} / \mathrm{mL})$. Percentages were calculated for patients with vitamin D insufficiency, further categorizing them into "insufficiency" and "deficiency" based on gender and race/ethnicity. A cut off point of $<20 \mathrm{ng} / \mathrm{mL}$ and $<$ $30 \mathrm{ng} / \mathrm{mL}$ was used for specifying vitamin D deficiency and insufficiency. Values are presented as mean \pm standard deviation. One-way ANOVA analyses were performed to determine any significant difference in the mean $25(\mathrm{OH}) \mathrm{D}$ serum based on gender and also based on race/ethnicity. A $P$ value of $<0.05$ was considered to indicate statistical significance. Further, odds ratio (OR) was computed to ascertain any relationship between vitamin D insufficiency and elevated BMI.

\section{Results}

Baseline characteristics of the total study population including patients with and without vitamin D insufficiency are presented in Table 1. The study included $80(39.2 \%)$ male and $124(60.8 \%)$ female patients. The average age for the entire population was 63.3 years with no significant mean age difference between male and female. Out of 204 patients, 53.4\% $(\mathrm{n}=109)$ were found to have vitamin $\mathrm{D}$ insufficiency $($ mean $25(\mathrm{OH}) \mathrm{D}=20.1 \mathrm{ng} / \mathrm{mL})$, while $46.6 \%(\mathrm{n}=$ 95 ) were within the normal range (mean $25(\mathrm{OH}) \mathrm{D}=37.8$ $\mathrm{ng} / \mathrm{mL}$ ). What seemed to be remarkable was that the mean serum $25(\mathrm{OH}) \mathrm{D}$ of the total study population was 28.3 , indicating a general trend of vitamin D insufficiency in patients treated at the cardiology clinic. It was observed that among African Americans, $74.3 \%$ (26 out of 35) had vitamin D insufficiency while $42.3 \%$ (79 out of 164) of whites had the same. Overall, $82.8 \%$ of the total population was overweight with a mean BMI of 29.5 . Additionally, $86.2 \%$ of the population with vitamin D insufficiency had a higher BMI of 30.2 in comparison to population without vitamin D insufficiency.

Further analysis was undertaken to ascertain serum $25(\mathrm{OH}) \mathrm{D}$ insufficiency $(<30 \mathrm{ng} / \mathrm{mL})$ and deficiency $(<20.0$ $\mathrm{ng} / \mathrm{mL}$ ) based on gender and race/ethnicity (Table 2). With respect to gender, female patients were more likely to be vitamin D deficient. However, a one-way ANOVA analysis did not reveal any significant variation in the mean vitamin $\mathrm{D}$ serum level between male and female patients $(\mathrm{P}$ value $=0.16$ ).

In regard to race/ethnicity, white patients were more likely to have vitamin D insufficiency than deficiency. Percentage of patients having vitamin D deficiency and insufficiency was quite similar among African Americans. The analysis revealed that white male patients had more vitamin D insufficiency (68.8\%) followed by African American female patients (52.9\%) whereas African American male patients had more vitamin D deficiency (55.6\%) followed by white female patients $(51.1 \%)$. No significant difference in the mean serum 25(OH)D level was found between white and African American patients based on one-way ANOVA analysis $(\mathrm{P}$ value $=0.09)$.

The comparison of mean serum $25(\mathrm{OH}) \mathrm{D}$ and mean BMI for population with vitamin D insufficiency based on gender and race/ethnicity is shown in Figure 1. Though their cardiac manifestations were wide-ranging that included atrial fibrillation, left ventricular hypertrophy, coronary artery disease, PAD, stable and unstable angina, it was apparent that the mean vitamin $\mathrm{D}$ serum level was relatively low across the broad spectrum of CVD. African Americans, especially women had both high mean BMI and low serum 25(OH)D level. The calculated OR (1.67) revealed that patients with a higher BMI $(\geq 25)$ were more likely to have vitamin D insufficiency.

\section{Discussion}

Vitamin D deficiency and the risk of CVD has been well established in previous studies [28-31]. The Framingham Offspring Study suggested that moderate to severe vitamin 


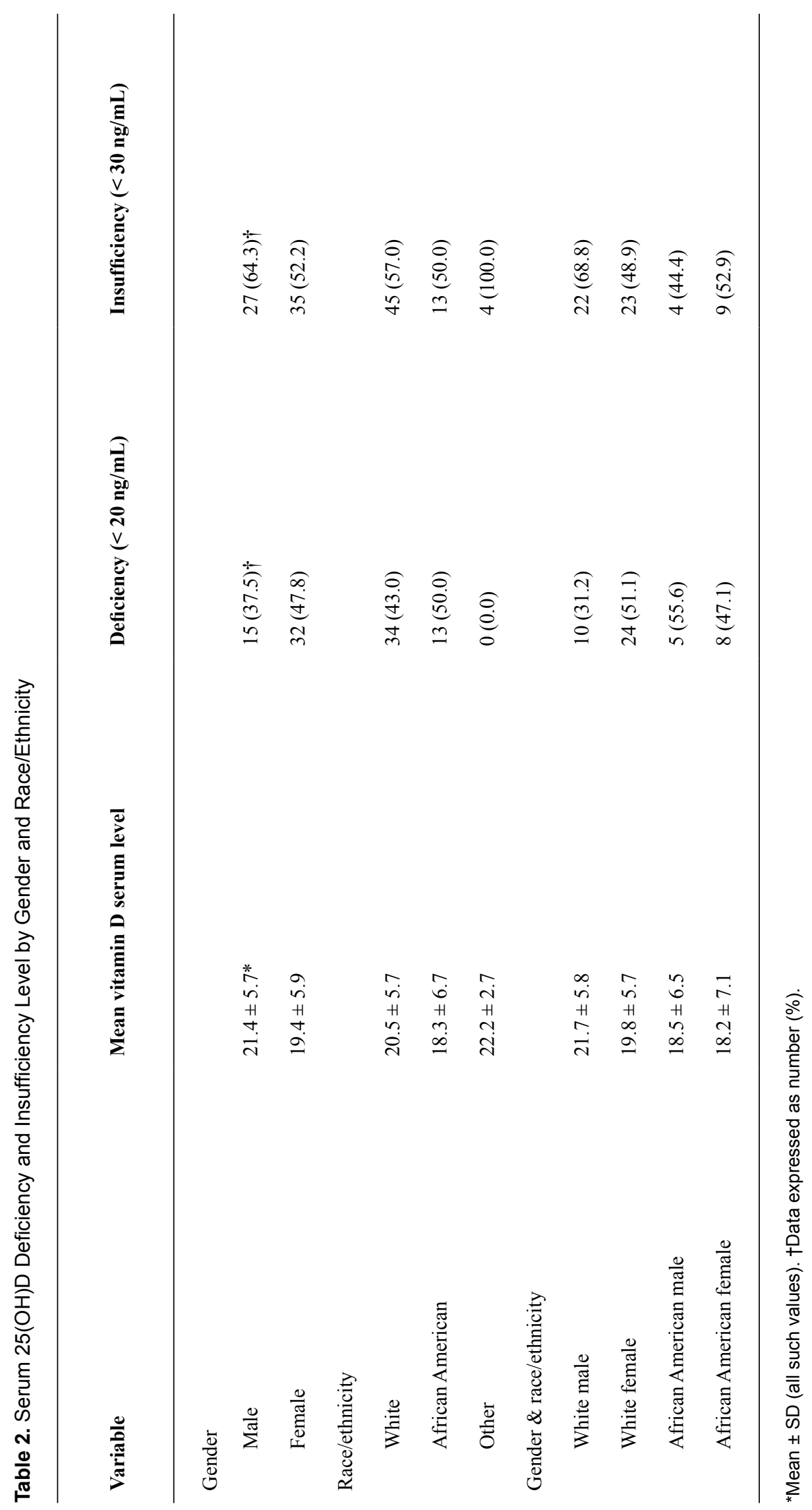




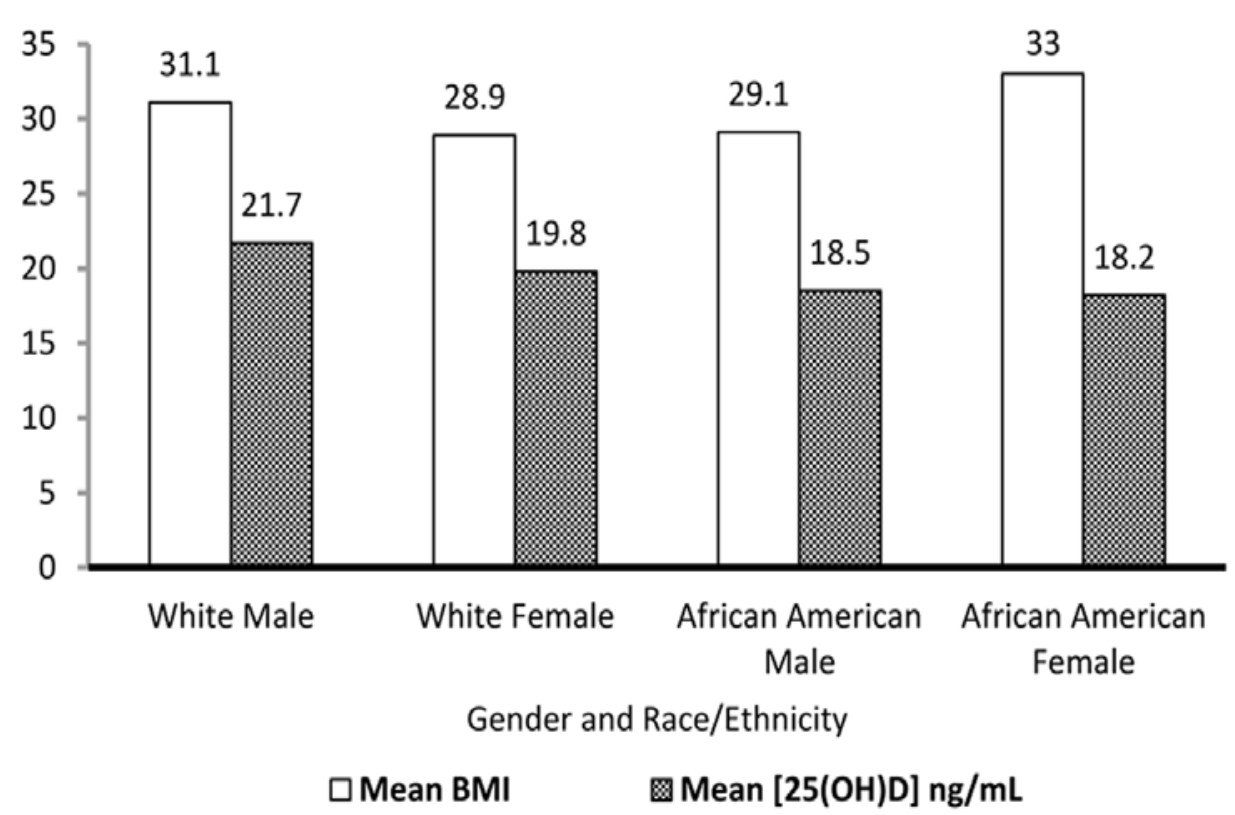

Figure 1. Mean serum 25(OH)D concentration and BMI of population with vitamin $\mathrm{D}$ insufficiency categorized by gender and race/ethnicity.

D deficiency is a risk factor for developing CVD [32]. The Copenhagen City Heart Study observed stepwise increases in the risk of heart disease as serum 25(OH)D level declined [33]. Ecological studies have reported that higher rates of CVD with increasing distance from the equator often attributed to the higher prevalence of vitamin D deficiency in colder climates and less exposure to sunlight [34-36]. Our study however focused on vitamin D insufficiency and the Southern Alabama gulf-coast region that has a high average temperature along with a high number of sunny days and an elevated UV ray index. The study substantiated the fact that vitamin D insufficiency levels exist in the coastal south-eastern region of the United States in spite of the high annual number of sunny days, and elevated UV ray index. In the University cardiovascular clinic setting, $53.4 \%$ of patients were found to have vitamin D insufficiency $(<30 \mathrm{ng} /$ $\mathrm{mL}$ ). Further, patients with a higher BMI were more likely to have lower Vitamin D serum levels. It is believed that these findings would be of relevance in clinical practice in the south-eastern region and other geographic areas with similar temperature, UV ray index, and topography. It is of interest to note that another study undertaken in Hawaii found that $51 \%$ of the population studied $(\mathrm{n}=93)$ had low Vitamin D status using a cut point of $30 \mathrm{ng} / \mathrm{mL}$ [37]. Our study's limitation is the relatively small sample size of 204 patients. This limitation may be somewhat ameliorated by the fact that all patients studied were receiving active treatment in the University Cardiology clinic and thereby of specific relevance to the field of cardiology.

\section{Conclusion}

This study provides a perspective that vitamin D insufficiency levels are simply not limited to colder climates and higher altitudes. Further, patients with a higher BMI had an increased risk of vitamin D insufficiency. More large scale and extensive studies should be conducted in similar climates to further assess vitamin D insufficiency in cardiac patients to help establish guidelines for clinical practice.

\section{References}

1. Rosen CJ. Clinical practice. Vitamin D insufficiency. $\mathrm{N}$ Engl J Med. 2011;364(3):248-254.

2. Lee JH, O'Keefe JH, Bell D, Hensrud DD, Holick MF. Vitamin D deficiency an important, common, and easily treatable cardiovascular risk factor? J Am Coll Cardiol. 2008;52(24):1949-1956.

3. Vacek JL, Vanga SR, Good M, Lai SM, Lakkireddy D, Howard PA. Vitamin D deficiency and supplementation and relation to cardiovascular health. Am J Cardiol. 2012;109(3):359-363.

4. Holick MF. Vitamin D deficiency. N Engl J Med. 2007;357(3):266-281.

5. Looker AC, Dawson-Hughes B, Calvo MS, Gunter EW, Sahyoun NR. Serum 25-hydroxyvitamin D status of adolescents and adults in two seasonal subpopulations from NHANES III. Bone. 2002;30(5):771-777. 
6. Reynolds JA, Haque S, Berry JL, Pemberton P, Teh LS, Ho P, Gorodkin R, et al. 25-Hydroxyvitamin D deficiency is associated with increased aortic stiffness in patients with systemic lupus erythematosus. Rheumatology (Oxford). 2012;51(3):544-551.

7. Azali P, Barbasso Helmers S, Kockum I, Olsson T, Alfredsson L, Charles PJ, Piehl Aulin K, et al. Low serum levels of vitamin D in idiopathic inflammatory myopathies. Ann Rheum Dis. 2013;72(4):512-516.

8. Rossini M, Maddali Bongi S, La Montagna G, Minisola G, Malavolta N, Bernini L, Cacace E, et al. Vitamin D deficiency in rheumatoid arthritis: prevalence, determinants and associations with disease activity and disability. Arthritis Res Ther. 2010;12(6):R216.

9. Damasiewicz MJ, Magliano DJ, Daly RM, Gagnon C, Lu ZX, Ebeling PR, Chadban SJ, et al. 25-Hydroxyvitamin D levels and chronic kidney disease in the AusDiab (Australian Diabetes, Obesity and Lifestyle) study. BMC Nephrol. 2012;13:55.

10. Navaneethan SD, Schold JD, Arrigain S, Jolly SE, Jain A, Schreiber MJ, Jr., Simon JF, et al. Low 25-hydroxyvitamin D levels and mortality in non-dialysis-dependent CKD. Am J Kidney Dis. 2011;58(4):536-543.

11. Thadhani R, Appelbaum E, Pritchett Y, Chang Y, Wenger J, Tamez H, Bhan I, et al. Vitamin D therapy and cardiac structure and function in patients with chronic kidney disease: the PRIMO randomized controlled trial. JAMA. 2012;307(7):674-684.

12. Bee CR, Sheerin DV, Wuest TK, Fitzpatrick DC. Serum vitamin D levels in orthopaedic trauma patients living in the northwestern United States. J Orthop Trauma. 2013;27(5):e103-106.

13. Angeline ME, Gee AO, Shindle M, Warren RF, Rodeo SA. The effects of vitamin D deficiency in athletes. Am J Sports Med. 2013;41(2):461-464.

14. Bogoch ER, Elliot-Gibson V, Wang RY, Josse RG. Secondary causes of osteoporosis in fracture patients. J Orthop Trauma. 2012;26(9):e145-152.

15. Holick MF, Binkley NC, Bischoff-Ferrari HA, Gordon CM, Hanley DA, Heaney RP, Murad MH, et al. Evaluation, treatment, and prevention of vitamin D deficiency: an Endocrine Society clinical practice guideline. J Clin Endocrinol Metab. 2011;96(7):1911-1930.

16. Gulseth HL, Gjelstad IM, Birkeland KI, Drevon CA. Vitamin D and the metabolic syndrome. Curr Vasc Pharmacol. 2013;11(6):968-984.

17. Adams JS, Hewison M. Update in vitamin D. J Clin Endocrinol Metab. 2010;95(2):471-478.

18. Anagnostis P, Athyros VG, Adamidou F, Florentin M, Karagiannis A. Vitamin D and cardiovascular disease: a novel agent for reducing cardiovascular risk? Curr Vasc Pharmacol. 2010;8(5):720-730.

19. Giovannucci E, Liu Y, Hollis BW, Rimm EB. 25-hydroxyvitamin $\mathrm{D}$ and risk of myocardial infarc- tion in men: a prospective study. Arch Intern Med. 2008;168(11):1174-1180.

20. McGreevy C, Williams D. New insights about vitamin $\mathrm{D}$ and cardiovascular disease: a narrative review. Ann Intern Med. 2011;155(12):820-826.

21. Braun LA, Spitzer O, Levkovich B, et al. Prevalence of Vitamin D Deficiency Prior to Cardiothoracic Surgery. Heart Lung Circ. 2014.

22. Thacher TD, Clarke BL. Vitamin D insufficiency. Mayo Clin Proc. 2011;86(1):50-60.

23. National Weather Service. http://forecast.weather.gov/ MapClick.php?lat=30.69\&lon=-88.05.

24. http://www.currentresults.com/Weather/Alabama/annual-days-of-sunshine.php.

25. Environment Protection Agency. http://www.epa.gov/ sunwise/uvimonth.html.

26. Prentice A. Vitamin D deficiency: a global perspective. Nutr Rev. 2008;66(10 Suppl 2):S153-164.

27. Lavie CJ, Lee JH, Milani RV. Vitamin D and cardiovascular disease will it live up to its hype? J Am Coll Cardiol. 2011;58(15):1547-1556.

28. Anderson JL, May HT, Horne BD, Bair TL, Hall NL, Carlquist JF, Lappe DL, et al. Relation of vitamin D deficiency to cardiovascular risk factors, disease status, and incident events in a general healthcare population. Am J Cardiol. 2010;106(7):963-968.

29. Kendrick J, Targher G, Smits G, Chonchol M. 25-Hydroxyvitamin D deficiency is independently associated with cardiovascular disease in the Third National Health and Nutrition Examination Survey. Atherosclerosis. 2009;205(1):255-260.

30. Grandi NC, Breitling LP, Vossen CY, Hahmann H, Wusten B, Marz W, Rothenbacher D, et al. Serum vitamin D and risk of secondary cardiovascular disease events in patients with stable coronary heart disease. Am Heart J. 2010;159(6):1044-1051.

31. Norman PE, Powell JT. Vitamin D and cardiovascular disease. Circ Res. 2014;114(2):379-393.

32. Wang TJ, Pencina MJ, Booth SL, Jacques PF, Ingelsson E, Lanier K, Benjamin EJ, et al. Vitamin D deficiency and risk of cardiovascular disease. Circulation. 2008;117(4):503-511.

33. Brondum-Jacobsen P, Benn M, Jensen GB, Nordestgaard BG. 25-hydroxyvitamin $\mathrm{d}$ levels and risk of ischemic heart disease, myocardial infarction, and early death: population-based study and meta-analyses of 18 and 17 studies. Arterioscler Thromb Vasc Biol. 2012;32(11):2794-2802.

34. Grimes DS, Hindle E, Dyer T. Sunlight, cholesterol and coronary heart disease. QJM. 1996;89(8):579-589.

35. Fleck A. Latitude and ischaemic heart disease. Lancet. 1989;1(8638):613.

36. Borissova AM, Shinkov A, Vlahov J, Dakovska L, Todorov T, Svinarov D, Kassabova L. Vitamin D status 
in Bulgaria--winter data. Arch Osteoporos. 2013;8(12):133.

37. Binkley N, Novotny R, Krueger D, Kawahara T, Daida
YG, Lensmeyer G, Hollis BW, et al. Low vitamin D status despite abundant sun exposure. J Clin Endocrinol Metab. 2007;92(6):2130-2135. 